Endocrinol. Japon. 1969, 16 (6), 653 663

\title{
Effect of Androgen and Estrogen on the Hydroxylation of Steroid Hormones by Rat Liver Microsomes
}

\author{
RYUICHI KATO, ATSUSHI TAKAHASHI \\ AND YOSHIHITO OMORI \\ Department of Pharmacology, National Institute of \\ Hygienic Sciences, Setagaya-ku, Tokyo
}

\begin{abstract}
Synopsis
Castration in male rats decreased the activities of testosterone and progesterone hydroxylations and reduced the magnitude of spectral change caused by testosterone and progesterone in liver microsomes, accompanying less marked decrease in microsomal P-450 content and NADPH-neotetrazolium reductase activities. The administration of testosterone or methyltestosterone to the castrated rats completely restored the hydroxylating activities and magnitude of the spectral change. The simultaneous injection of estradiol or diethylstilbestrol blocked the action of the androgens. These results suggest that androgen increases the binding capacity of P-450 with steroid hormones, and makes an increase in the hydroxylating activities and that estrogen directly prevents the above action of androgen.
\end{abstract}

A number of foreign compounds of high lipid-solubility are oxidatively metabolized to more water-soluble compounds by the liver microsomal hydroxylase system, called drugmetabolizing enzymes, in the presence of NADPH and oxygen (Brodie et al., 1958; Gillette, 1963). It has been well known that the activities of drug-metabolizing enzymes are higher in male rats than in female ones (Quinn et al., 1958; Gillette, 1963; Kato and Gillette, 1965). These activities are stimulated by anabolic action of androgen and simultaneous administration of estrogen blocks the action of androgen (Kato et al., 1962; Booth and Gillette, 1962; Kato and Onoda, 1969).

On the other hand, recent works of Conney and Klutch (1963), Kuntzman et al. (1964) and Conney et al. (1965) have shown that liver microsomal enzymes hydroxylate various steroid hormones in the presence of NADPH and oxygen and that there are many similarities between the natures of drug-metabolizing enzymes and those of steroid hydroxylating enzymes. The activities of both enzymes are

Received for publication December 24, 1969. higher in microsomes from adult male rats than in those from adult female rats, and these enzyme systems have similar intracellular distribution, cofactor requirement and response to the administration of some drugs.

In the present communication, therefore, the effect of androgen and estrogen on the activities of testosterone and progesterone hydroxylations has been investigated. Since the involvement of cytochrome P-450 as the oxygen-activating enzyme and substrate-binding site in the hydroxylation of drugs and steroid hormones has been reported (Omura et al., 1965; Kato, 1966; Imai and Sato, 1967; Schenkman et al., 1967a), the effects of androgen and estrogen on the content of cytochrome P-450 and the spectral changes of $\mathrm{P}-450$ caused by testosterone and progesterone have been investigated in relation to the examination of hydroxylating activity of testosterone and progesterone.

\section{Materials and Methods}

\section{Animals}

Male and female rats of the Wistar strain, weighing 
about 160 and $180 \mathrm{~g}$, respectively, were used.

Male rats were castrated 23 days before sacrifice and treated daily with testosterone propionate $(5$ $\mathrm{mg} / \mathrm{kg})$, methyltestosterone $(5 \mathrm{mg} / \mathrm{kg})$, estradiol benzoate $(500 \mu \mathrm{g} / \mathrm{kg})$, diethylstilbestrol dibenzoate $(500$ $\mu \mathrm{g} / \mathrm{kg}$ ) for 10 days before being killed. All the steroids were dissolved in olive oil and given subcutaneously with a volume of $1 \mathrm{ml}$ per $\mathrm{kg}$ body weight. Control and castrated rats received only olive oil.

\section{Chemicals}

NADP, glucose 6-phosphate and glucose 6-phosphate dehydrogenase were purchased from Böhringer and Soehne $\mathrm{GmbH}$, Germany. Progesterone-4- ${ }^{14} \mathrm{C}$ (specific activity, $58.5 \mathrm{mc} / \mathrm{mmole}$ ) and testosterone-4${ }^{14} \mathrm{C}$ (specific activity, $29.2 \mathrm{mc} / \mathrm{mmole}$ ) were purchased from Daiichi Kagaku Co., Ltd., Japan. 16 $\alpha$-Hydroxyprogesterone was kindly supplied by Prof. H. Solomon, $6 \beta$-hydroxytestosterone, $7 \alpha$-hydroxytestosterone and $16 \alpha$-hydroxytestosterone were kindly supplied by Dr. A. H. Conney and Dr. A. Nehr. Other metabolites of progesterone and testosterone were purchased from Sigma, U.S.A. Other chemicals were of reagent grade and purchased from commercial sources.

\section{Preparation of microsomal fraction}

The rats were decapitated, and the liver was removed, chopped into small pieces, washed thoroughly and homogenized with 3 volumes of $1.15 \% \mathrm{KCl}$ in a Teflon-glass homogenizer. The homogenate was centrifuged at $10,000 \mathrm{Xg}$ and the supernatant fluid was then centrifuged for $60 \mathrm{~min}$ at $105,000 \mathrm{Xg}$. The supernatant fluid and microsomal pellet were separated by decantation, and the microsomal pellet was rinsed once and suspended in $1.15 \% \mathrm{KCl}$ solution.

\section{Assay of NADPH-neotetrazolium reductase}

The activity of NADPH-neotetrazolium reductase was determined according to the method described in a previous paper (Kato and Takanaka, 1968).

\section{Determination of microsomal protein and cyto-} chrome P-450 contents

The protein content of microsomal fraction was measured according to the method of Lowry et al. (1952). The content of cytochrome P-450 was determined according to the method of Omura and Sato (1964) as described in the previous paper (Kato and Onoda, 1969). The content of cytochrome P-450 was expressed as $\mathrm{m} \mu$ mole per $\mathrm{mg}$ microsomal protein according to Omura and Sato (1964).

\section{Metabolism of testosterone and progesterone by liver microsomes}

A typical incubation mixture consisted of microsomal suspension equivalent to $250 \mathrm{mg}$ or $500 \mathrm{mg}$ of liver tissue, $20 \mu$ moles of glucose 6-phosphate 1.0 $\mu$ mole of NADP, 1.5 international units of glucose 6 phosphate dehydrogenase, $50 \mu$ moles of nicotinamide, $25 \mu$ moles of $\mathrm{MgCl}_{2}, 1.4 \mathrm{ml}$ of $0.2 \mathrm{M}$ sodium phosphate buffer, $\mathrm{pH} 7.4,1 \mu$ mole $(0.6 \mu \mathrm{c})$ of testosterone or progesterone, $0.5 \mathrm{ml}$ of $1.15 \% \mathrm{KCl}$ solution and water to a final volume of $5.0 \mathrm{~m} l$. The mixture was incubated aerobically at $37^{\circ} \mathrm{C}$ for $10 \mathrm{~min}$.

The steroids and their metabolites present in $5 \mathrm{ml}$ portions of the incubation mixture were extracted with $30 \mathrm{ml}$ of dichloromethane by shaking for $20 \mathrm{~min}$. A $20-\mathrm{m} l$ portion of the organic phase was evaporated to dryness by a rotary evaporator below $50^{\circ} \mathrm{C}$ and the residue was redissolved in $0.25 \mathrm{ml}$ of ethanol. An exact portion $(0.5 \mathrm{ml})$ of the ethanol solution was applied on Toyo No.50 filter paper for chromatography. Testosterone and its metabolites were chromatographed (descending) for $4 \mathrm{hr}$ at $25^{\circ} \mathrm{C}$ with the upper phase of a toluene-methanol-water system (2:1:1 by vol.) as described by Conney and Klutch (1963). Progesterone and its metabolites were chromatographed (ascending) overnight at $25^{\circ} \mathrm{C}$ with the upper phase of a cyclohexan-dioxane-methanol-water system (100:25:100:10 by vol.) as described by Conney and Klutch (1963). The radioactivity on the chromatogram was measured by a radiochromatogram scanner (Packard 7201). Further separation and identification of the metabolites of testosterone and progesterone were carried out with thin-layer chromatography through the methods of acetylation by acetic anhydrate and of oxidation by chromic acid as described in the previous papers (Kato et al., 1970a; Kato et al., 1970b) according to Shikita et al. (1964). In some experiments, the incubation under nitrogen atmosphere instead of air was carried out for the criteria of the hydroxylated metabolites.

\section{Determination of substrate-induced difference spectra}

The spectral changes caused by testosterone and progesterone were determined according to Schenkman et al. (1967b) as described in a previous paper (Kato and Onoda, 1969). The substrate-induced difference spectra were recorded at room temperature with a Hitachi EPS-3T recording spectrophotometer with an integral sphere attachment. The concentration of microsomal protein was about $1.2 \mathrm{mg}$ per $\mathrm{ml}$ and the concentrations of testosterone and progesterone were $0.1 \mathrm{~m} M$. The results were expressed by $\triangle \mathrm{OD}$ per mg microsomal protein or $\mathrm{m} \mu$ mole P-450 per $\mathrm{m} l$.

\section{Results}

Effects of androgens and estrogens on 
Table 1. Effects of androgens and estrogens on liver microsomal protein content, and the weight of seminal vesicle and musclus levator ani

\begin{tabular}{lccc}
\hline \multicolumn{1}{c}{ Group } & $\begin{array}{c}\text { Microsomal protein } \\
(\mathrm{mg} / \mathrm{g} \text { wet organ weight })\end{array}$ & $\begin{array}{c}\text { Seminal vesicle } \\
(\mathrm{mg} / 100 \mathrm{~g} \text { body weight })\end{array}$ & $\begin{array}{c}\text { Levator ani muscle } \\
(\mathrm{mg} / 100 \mathrm{~g} \text { body weight })\end{array}$ \\
\hline Male control & $28.5 \pm 0.4$ & $238 \pm 14$ & $65 \pm 4$ \\
Castrated & $27.9 \pm 0.4$ & $23 \pm 4$ & $21 \pm 3$ \\
Castrated & $-2 \%$ & $-90 \%^{*}$ & $-68 \%^{*}$ \\
+ TS & $28.3 \pm 0.3$ & $598 \pm 50$ & $98 \pm 5$ \\
Castrated & $-1 \%$ & $+151 \% *$ & $+51 \%^{*}$ \\
+ TS + ED & $27.8 \pm 0.5$ & $671 \pm 61$ & $102 \pm 6$ \\
Castrated & $-2 \%(-2 \%)$ & $+181 \% *(+12 \%)$ & $+57 \%^{*}(+4 \%)$ \\
+ TS + DES & $28.4 \pm 0.6$ & $650 \pm 53$ & $103 \pm 8$ \\
Castrated & $0 \%(0 \%)$ & $+173 \% *(+9 \%)$ & $+59 \%^{*}(+5 \%)$ \\
+ MT & $28.8 \pm 0.4$ & $421 \pm 43$ & $85 \pm 4$ \\
Castrated & $+1 \%$ & $+77 \% *$ & $+31 \% *$ \\
+ MT + ED & $27.6 \pm 0.3$ & $463 \pm 45$ & $98 \pm 6$ \\
Castrated & $-3 \%(-4 \%)$ & $+95 \% *(+10 \%)$ & $+50 \% *(+15 \%)$ \\
+ MT + DES & $28.3 \pm 0.5$ & $430 \pm 36$ & $86 \pm 5$ \\
Female control & $-1 \%(-2 \%)$ & $+81 \% *(+2 \%)$ & $+32 \% *(+1 \%)$ \\
& $28.0 \pm 0.3$ & - & - \\
\hline
\end{tabular}

Male rats were castrated 23 days before the experiments, then treated for 10 days with testosterone (TS) $(5 \mathrm{mg} / \mathrm{kg}$, s.c.), methyltestosterone (MT) $(5 \mathrm{mg} / \mathrm{kg}$, s.c.), estradiol (ED) or diethylstilbestrol (DES) $(500 \mu \mathrm{g} / \mathrm{kg}, \mathrm{s.c}$.) alone or combined as indicated in the table. The results are given as averages $\pm \mathrm{S}$.E. obtained from 6 determinations. The figures with + or - indicate the percentage difference from controls and the figures in the parentheses indicate the percentage difference from the castrated + TS treated rats or the castrated + MT treated rats. The asterisks in the table indicate the significant difference $(\mathrm{p}<0.05)$.

liver microsomal protein, and weights of seminal vesicle and levator ani muscle

Castration in male rats and treatments with androgens and estrogens did not alter the ratio of liver weight to body weight and the content of microsomal protein (Table 1). Castration markedly decreased the weights of seminal vesicle and levator ani muscle, and the treatment with testosterone or methyltestosterone increased their weights over the control values (Table 1). The simultaneous administration of estradiol or diethylstilbestrol failed to block the action of the androgens. These results indicate that the amount of the estrogens used in the present experiments is not enough to prevent the action of the androgens on the target organs.

Effects of androgens and estrogens on the content of cytochrome P-450 and activity of NADPH-neotetrazolium reductase

The content of cytochrome P-450 and the activity of NADPH-neotetrazolium reductase showed slight sex difference (Kato and Takahashi, 1968; Kato et al., 1968), and the effects of androgens and estrogens upon the electrontransport system were investigated in the present study.

Castration in male rats decreased slightly the content of cytochrome $\mathrm{P}-450$ and the activity of NADPH-neotetrazolium reductase (Table 2). The treatment with testosterone or methyltestosterone in the castrated rats restored the content of cytochrome P-450 and the activity of NADPH-neotetrazolium reductase to the control level. The administration of estradiol or diethylstilbestrol prevented the actions of 
Table 2. Effects of androgens and estrogens on microsomal P-450 content and NADPH-neotetrazolium (NT) reductase activity

\begin{tabular}{llc}
\hline \multicolumn{1}{c}{ Group } & $\begin{array}{c}\text { P-450 content } \\
(\mathrm{m} \mu \text { mole/mg protein })\end{array}$ & $\begin{array}{c}\text { NADPH-NT reductase } \\
(\mathrm{m} \mu \mathrm{mole} / \mathrm{mg} \text { protein } / \mathrm{min})\end{array}$ \\
\hline Male control & $0.87 \pm 0.03$ & $108 \pm 6$ \\
Castrated & $0.65 \pm 0.03$ & $73 \pm 5$ \\
& $-25 \% *$ & $-32 \%^{*}$ \\
Castrated & $0.89 \pm 0.05$ & $107 \pm 10$ \\
+ TS & $+2 \%$ & $-1 \%$ \\
Castrated & $0.69 \pm 0.04$ & $81 \pm 4$ \\
+ TS + ED & $-21 \% *(-22 \%)^{*}$ & $-25 \% *(-24 \%)^{*}$ \\
Castrated & $0.73 \pm 0.03$ & $86 \pm 6$ \\
+ TS + DES & $-16 \% *(-18 \%)^{*}$ & $-20 \% *(-20 \%)^{*}$ \\
Castrated & $0.85 \pm 0.04$ & $101 \pm 8$ \\
+ MT & $-2 \%$ & $-6 \%$ \\
Castrated & $0.69 \pm 0.03$ & $82 \pm 5$ \\
+ MT + ED & $-21 \% *(-18 \%)^{*}$ & $-24 \%^{*}(-19 \%)^{*}$ \\
Castrated & $0.72 \pm 0.04$ & $85 \pm 7$ \\
+ MT + DES & $-17 \% *(-15 \%)^{*}$ & $-21 \% *(-16 \%)$ \\
Female control & $0.60 \pm 0.03$ & $66 \pm 4$ \\
& $-30 \% *$ & $-39 \% *$ \\
\hline
\end{tabular}

See the legends for Table 1.

Table 3. Effects of androgens and estrogens on the metabolism of testosterone by liver microsomes

\begin{tabular}{|c|c|c|c|c|}
\hline \multirow{2}{*}{ Group } & \multicolumn{4}{|c|}{ Conversion of testosterone ( $\mathrm{m} \mu \mathrm{mole} / \mathrm{mg}$ protein $/ 10 \mathrm{~min})$} \\
\hline & Nonpolar peak & Polar peak $\mathrm{T} 1$ & Polar peak $\mathrm{T}_{2}$ & Polar peak $\mathrm{T}_{3}$ \\
\hline Male control & $18.6 \pm 1.3$ & $12.5 \pm 0.8$ & $16.8 \pm 0.5$ & $33.1 \pm 1.8$ \\
\hline \multirow[t]{2}{*}{ Castrated } & $47.7 \pm 2.3$ & $5.4 \pm 0.4$ & $5.9 \pm 0.8$ & $13.7 \pm 1.6$ \\
\hline & $+156 \% *$ & $-57 \% *$ & $-65 \% *$ & $-59 \% *$ \\
\hline Castrated & $19.4 \pm 1.8$ & $11.2 \pm 0.8$ & $15.9 \pm 1.1$ & $31.7 \pm 1.3$ \\
\hline$+\mathrm{TS}$ & $+10 \%$ & $-10 \%$ & $-5 \%$ & $-4 \%$ \\
\hline Castrated & $43.2 \pm 2.3$ & $6.5 \pm 0.9$ & $7.5 \pm 1.3$ & $16.4 \pm 1.6$ \\
\hline$+\mathrm{TS}+\mathrm{ED}$ & $+132 \% *$ & $-48 \% *$ & $-55 \% *$ & $-50 \% *$ \\
\hline Castrated & $44.4 \pm 2.7$ & $6.3 \pm 0.9$ & $9.4 \pm 1.3$ & $15.8 \pm 1.5$ \\
\hline$+\mathrm{TS}+\mathrm{DES}$ & $+140 \% *$ & $-50 \% *$ & $-44 \% *$ & $-52 \% *$ \\
\hline Castrated & $20.3 \pm 3.1$ & $12.3 \pm 1.3$ & $19.4 \pm 1.0$ & $29.3 \pm 2.1$ \\
\hline$+\mathrm{MT}$ & $+9 \%$ & $-2 \%$ & $+15 \%$ & $-11 \%$ \\
\hline Castrated & $45.2 \pm 2.4$ & $7.1 \pm 1.0$ & $7.9 \pm 1.5$ & $16.2 \pm 1.9$ \\
\hline$+\mathrm{MT}+\mathrm{ED}$ & $+143 \% *$ & $-43 \% *$ & $-53 \% *$ & $-51 \% *$ \\
\hline Castrated & $46.9 \pm 2.5$ & $5.8 \pm 0.7$ & $7.8 \pm 1.3$ & $14.8 \pm 1.7$ \\
\hline$+\mathrm{MT}+\mathrm{DES}$ & $+152 \% *$ & $-54 \% *$ & $-44 \%$ & $-55 \% *$ \\
\hline \multirow[t]{2}{*}{ Female control } & $50.1 \pm 2.2$ & $5.0 \pm 0.4$ & $5.1 \pm 0.4$ & $13.5 \pm 0.9$ \\
\hline & $+169 \% *$ & $-60 \% *$ & $-70 \% *$ & $-59 \% *$ \\
\hline
\end{tabular}

See the legends for Table 1. 


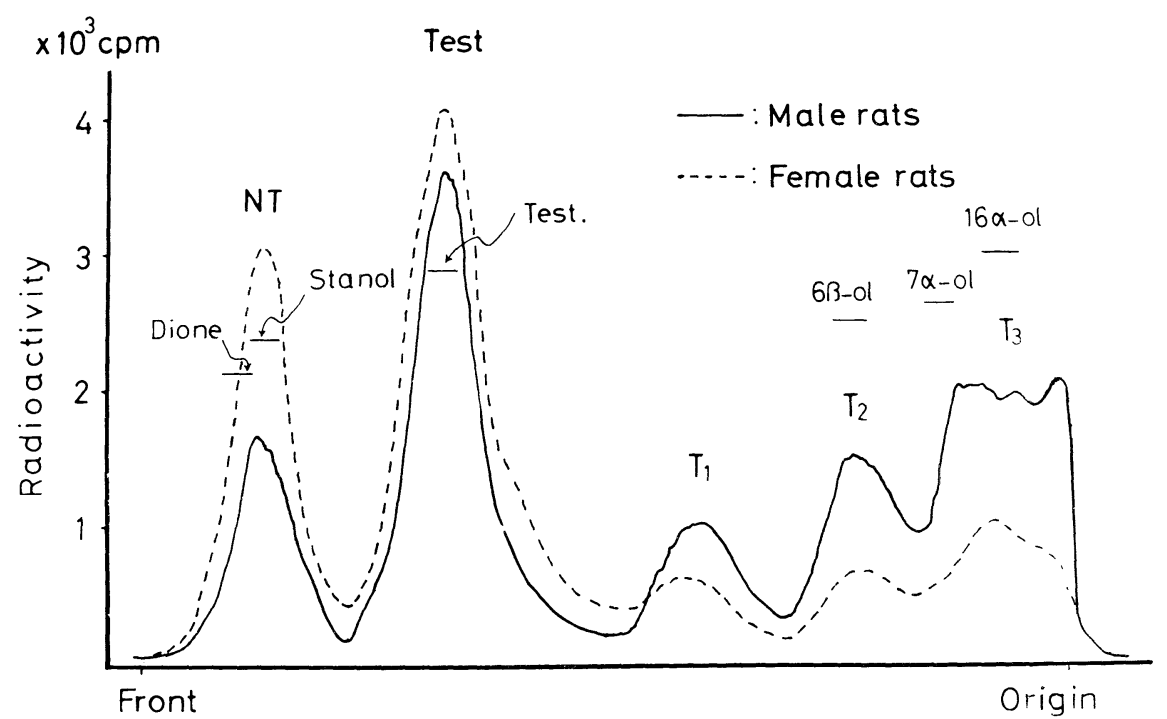

Fig. 1. Metabolism of testosterone by liver microsomes from male and female rats. After the incubation, testosterone and its metabolites were extracted with dichloromethane. The steroids were developed by descending paper chromatography with a toluene-methanol-water system $(2: 1: 1$ by vol.). The radioactivity was counted by a Packard radiochromatogram scanner. The mobility of authentic samples is indicated in the figure. (NT, nonpolar fraction; Test, testosterone fraction; $\mathrm{T}_{1}$ to $\mathrm{T}_{3}, \mathrm{~T}_{1}$ to $\mathrm{T}_{3}$ fractions; Dione, $5 \alpha \operatorname{tandrostan-3,17-}$ dione; Stanol, $5 \alpha$-androstan-17 $\beta$-ol-3-one; Test., testosterone; $6 \beta$-ol, $7 \alpha$-ol and $16 \alpha-\mathrm{ol}, 6 \beta-, 7 \alpha$ - and $16 \alpha-$ hydroxy testosterone)

the androgens on the content of P-450 and the activity of NADPH-neotetrazolium reductase. These results indicate that the content of cytochrome P-450 may be a minor factor responsible for the sex difference in the hydroxylation of steroid hormones.

\section{Effects of androgens and estrogens on} the metabolism of testosterone

As shown in Figure 1 and Table 3, there is a clear difference between male and female rats concerning the metabolic pattern of testosterone by liver microsomes.

The polar peaks $T_{1}, T_{2}$ and $T_{3}$, which were not obtained in the incubation under nitrogen atmosphere, contain the hydroxylated metabolites of testosterone, such as 6 $\beta$-hydroxytestosterone, $7 \alpha$-hydroxytestosterone and $16 \alpha$ hydroxytestosterone, although $\mathrm{T}_{1}$ - was not identified and supposed to contain $2 \alpha$-hydroxytestosterone, and the radioactivities of these polar peaks were higher in male rats than in female in agreement with the report of Kuntzman et al. (1964). The castration in male rats decreased the radioactivities of the polar peaks and the administration of androgens restored it to the level of intact male rats (Table 3). This action of the androgens was prevented by the simultaneous administration of estradiol or diethylstilbestrol.

As shown in Table 3 , the activity of $\Delta^{4}$ reductase for testosterone was lower in microsomes from the males than in those from the females and the activity seemed to be regulated by androgen in agreement with the report of Hagen and Troop (1960).

Activity of the enzymes for hydroxylation of testosterone per P-450 was higher in microsomes from the males than in those from the females (Table 5). The castration in the males decreased the activity of total hydroxylation of testosterone per P-450 and the administration 


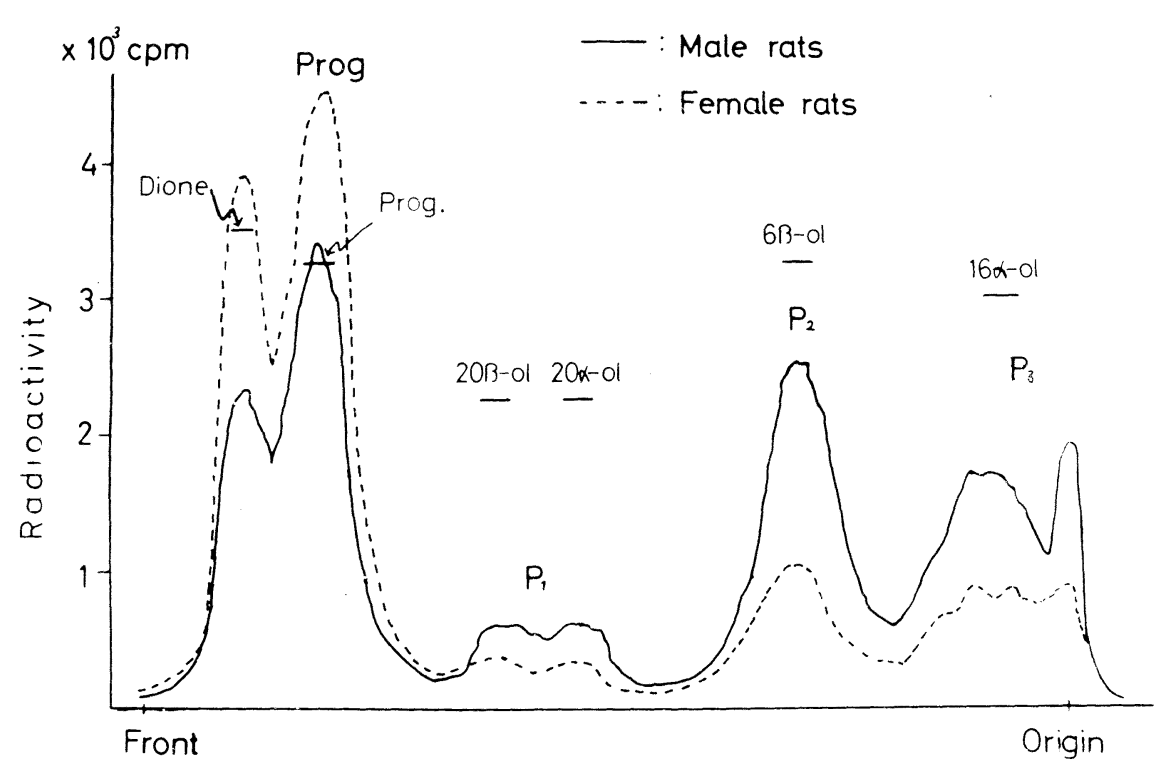

Fig. 2. Metabolism of progesterone by liver microsomes from male and female rats. After the incubation, progesterone and its metabolites were extracted with dichloromethane. The steroids were developed by ascending paper chromatography with a cyclohexan-dioxane-methanol-water system (100:25:100:10 by vol.). The mobility of authentic samples is indicated in the figure. (NP, nonpolar fraction; Prog, progesterone

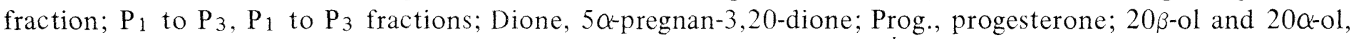
$20 \beta$ - and $20 \alpha$-hydroxy pregnan-4-en-3-ones; $6 \beta$-ol, $6 \beta$-hydroxyprogesterone; $16 \alpha$-ol, $16 \alpha$-hydroxy progesterone)

of androgens restored the hydroxylating activity to the level of the intact males. The action of the androgens was prevented to take place by the simultaneous administration of estrogens.

Since the combined administration of diethylstilbestrol or estradiol prevented the action of testosterone or methyltestosterone, the structure specificity for the actions of androgen and estrogen was assumed not to be highly estimated as already reported concerning the studies on the hydroxylation of drugs (Kato and Onoda, 1969). In addition, it is of interest to note that the action of androgens on the hydroxylating activity of liver microsomes is prevented by the low dose of estrogens which have failed to prevent the action of the androgens on the target organs.

Effects of androgens and estrogens on the metabolism of progesterone

As shown in Figure 2 and Table 4, there is a clear difference between the males and females concerning the metabolic pattern of progesterone by liver microsomes.

The polar peaks $\mathrm{P}_{2}$ and $\mathrm{P}_{3}$, which were not obtained by the incubation under nitrogen atmosphere, contain the hydroxylated metabolites of progesterone, such as 6 $\beta$-hydroxyprogesterone and 16 $\alpha$-hydroxyprogesterone, and the radioactivities of both polar peaks were higher in the males than in the females. The castration in the males decreased the radioactivities of both peaks and the administration of androgens restored the magnitude of the radioactivities to the level of the intact males (Table 4). The action of the androgens was prevented by the simultaneous administration of estrogens.

As shown in Table 4, the enzyme activity for 20-reduction of progesterone (polar peak $P_{1}$ ) was higher in microsomes from male rats than in those from the females; in contrast, the activity for $\Delta^{4}$-reduction of progesterone was 
Table 4. Effects of androgens and estrogens on the metabolisms of progesterone by liver microsomes

\begin{tabular}{|c|c|c|c|c|}
\hline \multirow{2}{*}{ Group } & \multicolumn{4}{|c|}{ Metabolism of progesterone $(\mathrm{m} \mu$ mole $/ \mathrm{mg}$ protein $/ 10 \mathrm{~min})$} \\
\hline & Nonpolar peak & Polar peak $\mathrm{P}_{1}$ & Polar peak $\mathrm{P}_{2}$ & Polar peak $\mathrm{P}_{3}$ \\
\hline Male control & $12.6 \pm 0.8$ & $6.7 \pm 0.8$ & $18.6 \pm 1.2$ & $15.6 \pm 1.2$ \\
\hline \multirow[t]{2}{*}{ Caștrated } & $20.6 \pm 0.9$ & $3.9 \pm 0.5$ & $5.8 \pm 0.6$ & $5.9 \pm 0.9$ \\
\hline & $+63 \% *$ & $-42 \% *$ & $-69 \% *$ & $-62 \% *$ \\
\hline Castrated & $11.7 \pm 0.7$ & $6.9 \pm 0.9$ & $21.2 \pm 0.6$ & $16.9 \pm 0.5$ \\
\hline$+\mathrm{TS}$ & $-7 \%$ & $+3 \%$ & $+13 \%$ & $+8 \%$ \\
\hline Castrated & $20.0 \pm 1.0$ & $4.0 \pm 0.6$ & $8.3 \pm 0.8$ & $5.3 \pm 0.7$ \\
\hline$+\mathrm{TS}+\mathrm{ED}$ & $+59 \% *$ & $-40 \% *$ & $-55 \% *$ & $-66 \% *$ \\
\hline Castrated & $16.8 \pm 0.4$ & $4.3 \pm 0.8$ & $9.6 \pm 0.7$ & $8.3 \pm 0.5$ \\
\hline$+\mathrm{TS}+\mathrm{DES}$ & $+33 \% *$ & $-36 \% *$ & $-48 \% *$ & $-47 \% *$ \\
\hline Castrated & $13.4 \pm 0.9$ & $6.5 \pm 0.8$ & $17.2 \pm 0.9$ & $14.5 \pm 0.7$ \\
\hline$+\mathrm{MT}$ & $+6 \%$ & $-3 \%$ & $-8 \%$ & $-7 \%$ \\
\hline Castrated & $19.4 \pm 1.1$ & $3.9 \pm 0.7$ & $8.0 \pm 1.2$ & $7.0 \pm 1.1$ \\
\hline$+\mathrm{MT}+\mathrm{ED}$ & $+54 \% *$ & $-42 \% *$ & $-57 \% *$ & $-55 \% *$ \\
\hline Castrated & $17.6 \pm 1.3$ & $4.2 \pm 0.6$ & $10.6 \pm 1.3$ & $8.8 \pm 1.4$ \\
\hline$+\mathrm{MT}+\mathrm{DES}$ & $+40 \% *$ & $-39 \% *$ & $-43 \% *$ & $-44 \% *$ \\
\hline \multirow[t]{2}{*}{ Female control } & $24.1 \pm 0.8$ & $2.8 \pm 0.5$ & $4.8 \pm 0.5$ & $5.4 \pm 0.4$ \\
\hline & $+91 \% *$ & $-58 \% *$ & $-74 \% *$ & $-65 \% *$ \\
\hline
\end{tabular}

See the legends for Table 1.

lower in the males than in the females. Both activities seemed to be regulated by androgen in agreement with the opinion of Hagen and Troop (1960).

The activity for total hydroxylation of progesterone per P-450 was higher in microsomes from the males than in those from the females (Table 5). The castration in the males decreased the activity for total hydroxylation of progesterone per P-450 and the administration of androgen restored the hydroxylating activity to the level of the intact males. The action of androgens was prevented by the simultaneous administration of estrogens. These results suggest that there may be other factor(s) responsible for the sex difference concerning the hydroxylation of steroid hormones, although the content of cytochrome P-450 is really involved in the sex difference.

Effects of androgens and estrogens on the magnitude of spectral changes caused by testosterone and progesterone
Recent studies have established that an unique hemoprotein called P-450 is involved as the oxygen-activating component in a number of NADPH-dependent monooxygenase reactions such as hydroxyiations of drugs and steroid hormones. Imai and Sato (1967), and Schenkman et al. (1967a) have reported that a number of drugs and steroid hormones, i.e. substrates of hepatic microsomal monooxygenases, react with the microsomal cytochrome to give two characteristic types of spectral changes, which are indicative of substrate interaction with cytochrome P-450 presumably representing the primary binding of substrate for enzymic hydroxylation.

Moreover, Schenkman et al. (1967b) have observed that the magnitude of spectral change caused by hexobarbital is greater in microsomes from male rats than in those from female. In a previous paper (Kato and Onoda, 1969), we have described that the magnitude of spectral change caused by hexobarbital is increased by treatment with androgens and that estrogens 
Table 5. Effects of androgens and estrogens on the activity of total hydroxylations of testosterone and progesterone

\begin{tabular}{|c|c|c|c|c|}
\hline \multirow{2}{*}{ Group } & \multicolumn{2}{|c|}{$\begin{array}{c}\text { Testosterone } \\
\text { total hydroxylation** }\end{array}$} & \multicolumn{2}{|c|}{$\begin{array}{c}\text { Progesterone } \\
\text { total hydroxylation*** }\end{array}$} \\
\hline & per mic. prot. & per $\mathrm{P}-450$ & per mic. prot. & per $\mathrm{P}-450$ \\
\hline Male control & $62.4 \pm 3.2$ & $72.1 \pm 3.6$ & $34.2 \pm 2.1$ & $39.3 \pm 2.5$ \\
\hline \multirow[t]{2}{*}{ Castrated } & $25.0 \pm 2.4$ & $38.1 \pm 2.0$ & $11.7 \pm 1.3$ & $18.0 \pm 1.2$ \\
\hline & $-60 \% *$ & $-43 \% *$ & $-66 \% *$ & $-54 \% *$ \\
\hline Castrated & $58.9 \pm 2.3$ & $66.1 \pm 3.4$ & $38.1 \pm 1.0$ & $42.8 \pm 1.9$ \\
\hline$+\mathrm{TS}$ & $-5 \%$ & $-8 \%$ & $+11 \%$ & $+8 \%$ \\
\hline Castrated & $30.4 \pm 2.7$ & $44.1 \pm 2.8$ & $13.6 \pm 1.5$ & $19.7 \pm 1.5$ \\
\hline$+\mathrm{TS}+\mathrm{ED}$ & $-51 \% *$ & $-39 \% *$ & $-60 \% *$ & $-50 \% *$ \\
\hline Castrated & $31.5 \pm 2.5$ & $43.2 \pm 2.3$ & $17.9 \pm 1.3$ & $25.9 \pm 1.9$ \\
\hline$+\mathrm{TS}+\mathrm{DES}$ & $-50 \% *$ & $-41 \% *$ & $-48 \% *$ & $-34 \% *$ \\
\hline Castrated & $61.0 \pm 4.8$ & $71.7 \pm 4.5$ & $31.7 \pm 1.5$ & $37.2 \pm 1.9$ \\
\hline$+\mathrm{MT}$ & $-2 \%$ & $-1 \%$ & $-7 \%$ & $-5 \%$ \\
\hline Castrated & $31.2 \pm 3.4$ & $45.2 \pm 3.3$ & $15.0 \pm 1.6$ & $21.7 \pm 1.5$ \\
\hline$+\mathrm{MT}+\mathrm{ED}$ & $-50 \% *$ & $-37 \% *$ & $-56 \% *$ & $-45 \% *$ \\
\hline Castrated & $28.4 \pm 2.9$ & $39.4 \pm 3.2$ & $19.4 \pm 2.1$ & $26.9 \pm 2.5$ \\
\hline$+\mathrm{MT}+\mathrm{DES}$ & $-54 \% *$ & $-45 \% *$ & $-43 \% *$ & $-32 \% *$ \\
\hline \multirow[t]{2}{*}{ Female control } & $23.6 \pm 2.0$ & $39.3 \pm 2.5$ & $10.2 \pm 0.9$ & $17.0 \pm 1.4$ \\
\hline & $-62 \% *$ & $-45 \% *$ & $-70 \% *$ & $-57 \% *$ \\
\hline
\end{tabular}

** Peak $\mathrm{T}_{1}$ plus Peak $\mathrm{T}_{2}$ and Peak $\mathrm{T}_{3}$ in Table 3.

*** Peak $\mathrm{P}_{2}$ plus Peak $\mathrm{P}_{3}$ in Table 4 .

The activity of total hydroxylation is indicated as $\mathrm{m} \mu$ mole hydroxylated metabolites formed per mg microsomal protein or per mumole P-450 for $10 \mathrm{~min}$.

See the legends for Table 1.

antagonize the effect of androgens.

In this connection, the effects of androgens and estrogens on the magnitude of spectral changes caused by testosterone and progesterone were investigated in the present study. As shown in Figure 3, a clear sex difference was observed in the spectral changes caused by testosterone and progesterone. The castration in the males decreased the magnitude of spectral change of cytochrome P-450 caused by testosterone (Table 6). The administration of androgens to the castrated rats restored the magnitude of the spectral change to the level of the intact males. The simultaneous administration of estrogens blocked the action of the androgens. Moreover, the magnitude of testosterone-induced spectral change per P-450 was also decreased by castration. The adminis- tration of androgens to the castrated rats restored the magnitude of the spectral change and the simultaneous administration of estrogens blocked the action of the androgens. Furthermore, the similar results were obtained with progesterone-induced spectral change (Table 6). These results suggest that the capacity of P-450 to interact with steroid hormones is increased by androgens, and estrogens block the action of the androgens. The alterations in the magnitude of the spectral changes were similar to those in the hydroxylating activities, and this suggests that the sex difference in the binding capacity of P-450 with testosterone and progesterone is a major factor responsible for the sex difference in the hydroxylating activities of steroid hormones by rat liver microsomes. 


\section{Progesterone difference spectrum}

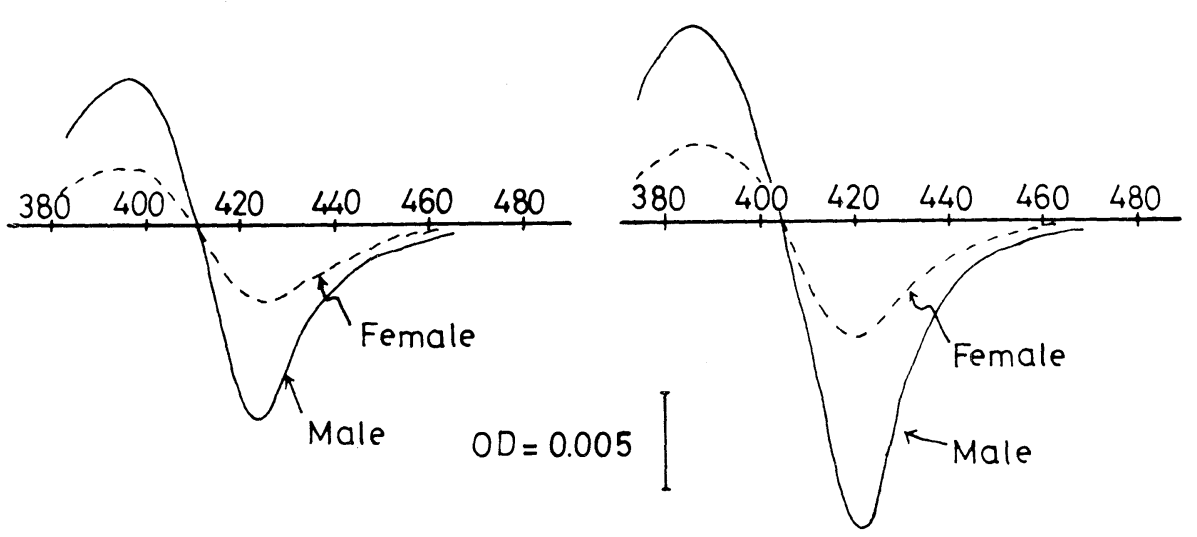

Fig. 3. The difference spectra of cytochrome P-450 induced by progesterone and testosterone in rat liver microsomes. The difference spectra were recorded on addition of progesterone $(0.1 \mathrm{~m} M)$ or testosterone into microsomal suspension $(1.2 \mathrm{mg}$ protein $/ \mathrm{m} l)$ isolated from male and female rats.

\section{Discussion}

In a previous paper (Kato and Onoda, 1969), we have demonstrated that castration in male rats decreases markedly the activity of hexobarbital hydroxylation, and decreases slightly the activity of NADPH-neotetrazolium reductase and the content of P-450. The magnitude of spectral change caused by hexobarbital is also decreased by the castration. Moreover, the administration of testosterone or methyltestosterone restores the hydroxylating activity and the magnitude of the spectral change to the level of the intact males and the simultaneous administration of estradiol or diethylstilbestrol counteracts the action of the androgens. These results are identical with the present results obtained with testosterone and progesterone which were used as the substrate in place of hexobarbital. Thus, as shown in Table 6, the decrease in the binding capacity of P-450 with the steroid substrate seems to be a factor responsible for the decrease in the activities of testosterone and progesterone hydroxylations.

The administration of estradiol or diethyl- stilbestrol to the castrated males or ovariectomized females did not result in any significant effect on the activities of testosterone and progesterone hydroxylations (Kato et al., 1969). These results suggest that the estrogens prevent directly the action of the androgens in the males. It has been recently observed that the action of androgen to increase the binding capacity of P-450 with the steroid substrate and the activities of testosterone and progesterone hydroxylations have been able to be demonstrated only in rats, but not in mice and rabbits (Kato et al., 1969). These results are consistent with our previous ones obtained as to the hydroxylation of hexobarbital (Kato et al., 1968; Kato and Onoda, 1969), and suggest that there is an androgen-dependent regulating mechanism which is common for drug-metabolizing enzymes and steroid hormone hydroxylase(s). However, this mechanism seems to be unwarrantable genetically in other species of animals (Kato et al., 1968).

At present, we have not known about the nature of the androgen-dependent regulating mechanism. According to the operon theory 
Table 6. Effects of androgens and estrogens on the magnitude of spectral changes induced by testosterone and progesterone

\begin{tabular}{|c|c|c|c|c|}
\hline \multirow{2}{*}{ Group } & \multicolumn{2}{|c|}{$\begin{array}{l}\text { Testosterone-induced } \\
\text { spectral change }\end{array}$} & \multicolumn{2}{|c|}{$\begin{array}{l}\text { Progesterone-induced } \\
\text { spectral change }\end{array}$} \\
\hline & per mic. prot. & per $P-450$ & per mic. prot. & per $\mathrm{P}-450$ \\
\hline Male control & $11.9 \pm 0.7$ & $13.6 \pm 0.8$ & $8.1 \pm 0.6$ & $9.3 \pm 0.8$ \\
\hline \multirow[t]{2}{*}{ Castrated } & $5.7 \pm 0.6$ & $8.8 \pm 0.7$ & $3.6 \pm 0.4$ & $5.5 \pm 0.6$ \\
\hline & $-52 \% *$ & $-35 \% *$ & $-56 \% *$ & $-41 \% *$ \\
\hline Castrated & $11.8 \pm 0.9$ & $13.3 \pm 1.1$ & $8.5 \pm 0.8$ & $9.5 \pm 0.9$ \\
\hline$+\mathrm{TS}$ & $-1 \%$ & $-2 \%$ & $+4 \%$ & $+2 \%$ \\
\hline Castrated & $6.1 \pm 0.6$ & $8.8 \pm 0.6$ & $3.7 \pm 0.3$ & $5.4 \pm 0.4$ \\
\hline$+\mathrm{TS}+\mathrm{ED}$ & $-49 \% *$ & $-35 \% *$ & $-54 \% *$ & $-42 \% *$ \\
\hline Castrated & $6.4 \pm 0.7$ & $8.8 \pm 0.7$ & $4.2 \pm 0.4$ & $5.7 \pm 0.7$ \\
\hline$+\mathrm{TS}+\mathrm{DES}$ & $-47 \% *$ & $-35 \% *$ & $-49 \% *$ & $-39 \% *$ \\
\hline Castrated & $11.8 \pm 1.1$ & $13.8 \pm 1.0$ & $7.8 \pm 0.9$ & $9.2 \pm 0.9$ \\
\hline$+\mathrm{MT}$ & $-1 \%$ & $+1 \%$ & $-4 \%$ & $-1 \%$ \\
\hline Castrated & $6.2 \pm 0.7$ & $9.0 \pm 0.8$ & $3.9 \pm 0.5$ & $5.7 \pm 0.6$ \\
\hline$+\mathrm{MT}+\mathrm{ED}$ & $-48 \% *$ & $-34 \% *$ & $-52 \% *$ & $-39 \% *$ \\
\hline Castrated & $5.8 \pm 0.6$ & $8.0 \pm 0.5$ & $4.4 \pm 0.4$ & $6.1 \pm 0.7$ \\
\hline$+\mathrm{MT}+\mathrm{DES}$ & $-51 \% *$ & $-41 \% *$ & $-46 \% *$ & $-34 \% *$ \\
\hline \multirow[t]{2}{*}{ Female control } & $5.4 \pm 0.4$ & $9.0 \pm 0.4$ & $3.3 \pm 0.3$ & $5.5 \pm 0.5$ \\
\hline & $-55 \% *$ & $-34 \% *$ & $-59 \% *$ & $-41 \% *$ \\
\hline
\end{tabular}

The change of absorbance between 420 and $500 \mathrm{~m} \mu$ on the addition of testosterone $(0.1 \mathrm{~m} M)$ was calculated from the testosterone-difference spectrum. The change of absorbance between 424 and $500 \mathrm{~m} \mu$ on the addition of progesterone $(0.1 \mathrm{mM})$ was calculated from the progesterone-difference spectrum. The magnitude of the spectral change is indicated as $\triangle \mathrm{OD} \times 10^{3}$ per $\mathrm{mg}$ microsomal protein or per m $\mu$ mole $\mathrm{P}-450$ per $\mathrm{ml}$.

See the legends for Table 1 .

of Jacob and Monod (1961), it was assumed that androgen might act as an inactivator to bind with an endogenous repressor, which may repress the action of a regulator gene responsible for the binding capacity of P-450 with substrates of the microsomal hydroxylases. The additional administration of estradiol or diethylstilbestrol counteracts the stimulative action of testosterone or methyltestosterone on the binding capacity of P-450 with the substrates (Table 6). It is thus assumed that, if androgen plays a role as an inactivator of the repressor, estrogen may interfere the binding of androgen with the repressor. Since estradiol and diethylstilbestrol counteract, to the same extent, the stimulative action of testosterone and methyltestosterone, the structure specificity for the binding of androgen with the re- pressor and interaction of estrogen with androgen are assumed not to be highly estimated.

Our further experiments have shown that the $\mathrm{Km}$ (Michaelis constant) values for the hydroxylation of testosterone and progesterone and the Ks (spectral dissociation constant) values for the spectral changes caused by testosterone and progesterone were together lower in microsomes from the males than in those from the females (Kato et al. , 1969). The $\mathrm{Km}$ and $\mathrm{Ks}$ values are, hence, supposed to be regulated by androgen (Kato and Onoda, 1969).

Our present results are in agreement with those observed as to hexobarbital hydroxylation and hexobarbital-induced spectral change (Kato and Onoda, 1969). We give, therefore, support to the view of Kuntzman et al. (1964) that the drugs and steroid hormones are hy- 
droxylated by the similar enzymes under the same mechanism.

As in the present studies each hydroxylated metabolite of the steroid hormones were not separated quantitatively, the hydroxylating activity was indicated as total hydroxylation. Heinrichs et al. (1967) recently pointed out that there was no clear sex difference concerning the $7 \alpha$-hydroxylation of testosterone in rat liver microsomes. More recently, Jacobson and Kuntzman (1969) reported evidence of the different response upon $7 \alpha$-hydroxylation, $6 \beta$-hydroxylation and $16 \alpha$-hydroxylation of testosterone in liver microsomes of rats with testosterone treatment. Their observations brought about the interesting relationships between the substrate binding with P-450 and hydroxylating activity for steroid hormones by rat liver microsomes in participation with the possible presence of cytochromes P-450 of more than two kinds and of terminal oxidases which determine the position of hydroxylation.

\section{Acknowledgements}

The authors are indebted to Prof. H. Solomon, Department of Biochemistry and Experimental Medicine, McGill University, Montreal, Canada, Dr. A. H. Conney, The Wellcome Research Laboratories, Burroughs Wellcome and Co. (U.S.A.), Tuckahoe, New York, N.Y., U.S.A., and Dr. A. Nehr, CIBA Research Institute, Basel, Switzerland, for supplying the standard sample of hydroxylated steroids.

\section{References}

Booth, J. and J. R. Gillette (1962). J. Pharmacol. Exptl. Therap. 137, 374.

Brodie, B. B., J. R. Gillette and B. N. La Du (1958). Ann. Rev. Biochem. 27, 427.

Conney, A. H. and A. Klutch (1963). J. Biol. Chem. 238, 1161.

Conney, A. H., K. Schneidman, M. Jacobson and R. Kuntzman (1965). Ann. N.Y. Acad. Sci. 123, 98 .

Gillette, J. R. (1963). Progr. Drug Res. 6, 13.

Hagen, A. A. and R. C. Troop (1960). Endocri- nology 67, 194.

Heinrichs, W. L., R. L. Mushen and A. Colás (1967). Steroids 9, 23.

Imai, Y. and R. Sato (1967). J. Biochem. (Tokyo) 62, 239.

Jacob, F. and J. Monod (1961). J. Mol. Biol. 3, 318.

Jacobson, M. and R. Kuntzman (1969). Steroids $13,327$.

Kato, R. (1966). J. Biochem. (Tokyo) 59, 574.

Kato, R., E. Chiesara and G. Frontino (1962). Biochem. Pharmacol. 11, 221.

Kato, R. and J. R. Gillette (1965). J. Pharmacol. Exptl. Therap. 151, 279.

Kato, R. and K. Onoda (1969). Biochem. Pharmacol. (in press).

Kato, R. and A. Takahashi (1968). Mol. Pharmacol. 4, 109.

Kato, R., A. Takahashi and Y. Omori (1970a). J. Biochem. (Tokyo) (submitted for publication).

Kato, R., A. Takahashi and Y. Omori (1970b). Biochim. Biophys. Acta. (in press).

Kato, R., A. Takahashi and K. Onoda (1969). unpublished observation.

Kato, R. and A. Takanaka (1968). Jap. J. Pharmacol. 18, 381.

Kato, R., A. Takanaka and M. Takayanagi (1968). Ibid. 18, 482.

Kuntzman, R., M. Jacobson, K. Schneidman and A. H. Conney (1964). J. Pharmacol. Exptl. Therap. 146, 280.

Lowry, O. H., H. J. Rosebrough, A. L. Farr and R. J. Randall (1961). J. Biol. Chem. 193, 265.

Omura, T. and R. Sato (1964). Ibid. 239, 2307.

Omura, T., R. Sato, D. Y. Cooper, O. Rosenthal and R. W. Estabrook (1965). Fed. Proc. 24, 1181.

Quinn, G. P., J. Axelrod and B. B. Brodie (1958). Biochem. Pharmacol. 1, 152.

Schenkman, J. B., H. Remmer and R. W. Estabrook (1967a). Mol. Pharmacol. 3, 113.

Schenkman, J. B., I. Frey, H. Remmer and R. W. Estabrook (1967b). Ibid. 3, 516.

Shikita, M., H. Kakizaki and B. Tamaoki (1964). Steroids 4, 521. 